\title{
Evaluating Metropolitan Hazard Risks under Extreme Rainstorms
}

\author{
Limin Zhang ${ }^{1,2}$, Shengyang Zhou $^{2}$, and Suzanne Lacasse ${ }^{3}$ \\ ${ }^{1}$ HKUST Shenzhen Research Institute, Nanshan, Shenzhen 518057, China. \\ ${ }^{2}$ Department of Civil and Environmental Engineering, Hong Kong University of Science and Technology, \\ Kowloon, Hong Kong, China. E-mail: cezhangl@ust.hk, szhouaq@connect.ust.hk \\ ${ }^{3}$ Norwegian Geotechnical Institute, Oslo, Norway. E-mail: $\underline{\text { Suzanne.lacasse@ngi.no }}$
}

\begin{abstract}
Half of the world's population lived in urban areas at the end of 2008. The United Nations predicted that by 2050 about $64 \%$ of the developing world and $86 \%$ of the developed world will be urbanized. A recent example is the rapid expansion of the Guangdong-Hong Kong-Macau Bay area, which has a population of over 60 million. In the changing climate, many metropolitans are exposed to multi-hazard risks, such as those caused by Hurricane Katrina in New Orleans in 2005, Hurricane Sandy in New York in 2012 and Typhoon Mangkhut in Hong Kong in 2018. How to cope with natural hazard risks in urban settings under the changing climate is an emerging issue. A large city is a system of many highly interactive sub-systems: social needs, transportation, utilities, communications etc. Five GREAT attributes of smart city systems should be advocated; namely Green, Resilient, Empowering, Adaptable, and Transformative. This paper focuses on the 'Resilience' aspect of cities when facing extreme storms, taking Hong Kong as a study city. The impact of recent rainstorms and typhoons on Hong Kong and the observed propagation of hazards among key systems of a city are briefed first. Then plausible rainstorms that may hit Hong Kong in the future are introduced. Subsequently, a numerical platform is presented to simulate the hazardous landslide, debris flow and flooding processes over the Hong Kong territory under extreme rainstorms. Finally, management strategies for coping with the extreme storms are discussed. The study helps identify catastrophic hazard scenarios and the bottlenecks in the urban disaster prevention systems, and assist policy making for improved preparedness and metropolitan safety.
\end{abstract}

Keywords: Natural hazards; resilience; smart city; climate change.

\section{GREAT Smart Cities Initiative}

Half of the world's population lived in urban areas at the end of 2008. The United Nations predicted that by 2050 about $64 \%$ of the developing world and $86 \%$ of the developed world will be urbanized. A recent example is the rapid expansion of the Guangdong-Hong Kong-Macau Bay area, which presently has a population of over 60 million. Recent severe rainstorms and storm surges led to catastrophic consequences in urban areas. For instance, Hurricane Katrina in New Orleans in August 2005 caused extensive failure of levees, leading to approximately 1500 fatalities. Hurricane Sandy in October 2012 in the east coast of the US led to 43 deaths and nearly 90,000 buildings in the inundation zone. In the future, more population and wealth will flux into large cities. How to cope with natural hazard risks in urban settings under the changing climate is an emerging issue.

A smart cities initiative was started at the Hong Kong University of Science and Technology, advancing five GREAT attributes of smart cities development, namely Green, Resilient, Empowering, Adaptable, and Transformative (Lo 2018):

1. Green: cities planned with due considerations for life-cycle environmental impacts, natural resources consumption (e.g. air, water, energy, materials) and waste generation and treatment;

2. Resilient: cities developed with infrastructure capacities and system redundancies to manage disruptions without severely affecting their essential functioning;

3. Empowering: cities designed for people, empowering wellbeing, efficiency, innovation, and productive partnerships;

4. Adaptable: cities designed with their infrastructure and systems adaptable to changes in new technology and global warming;

5. Transformative: cities designed for empowering their institutions and citizens to define and reposition their growth directions and strategies.

This paper focuses on the 'Resilience' aspect of cities under extreme storms. A large city is a system of many highly interactive sub-systems: social needs, transportation, utilities, communications etc. To enhance the resilience of such a complex system, it is essential to (1) identify future critical storm scenarios considering climate changes, (2) evaluate the urban system response under extreme rainstorms using appropriate hazard process modelling algorithms, (3) assess the multi-hazard risks, and (4) formulate risk mitigation strategies. These steps are known as "stress testing" (Zhang et al. 2017).

In this paper, the impact of recent rainstorms and typhoons on Hong Kong and observed propagation of hazards among key infrastructural systems are briefed first. Then plausible rainstorms that may hit Hong Kong in

Proceedings of the 7th International Symposium on Geotechnical Safety and Risk (ISGSR)

Editors: Jianye Ching, Dian-Qing Li and Jie Zhang

Copyright (c) ISGSR 2019 Editors. All rights reserved.

Published by Research Publishing, Singapore.

ISBN: 978-981-11-2725-0; doi:10.3850/978-981-11-2725-0_key6-cd 
the future are introduced. Subsequently, a numerical platform is presented to simulate the response of the entire Hong Kong territory to extreme rainstorms. Finally, green management strategies for coping with the extreme storms are discussed.

\section{Multi-Hazard Processes and Cascading Effects in Hong Kong under Recent Storm and Typhoon Events}

Hong Kong is well known to be a city prone to landslides due to its steep terrain and tropic climate. The Geotechnical Engineering Office (GEO)'s Enhanced Natural Terrain Landslide Inventory (ENTLI) records over 19,000 recent landslides in the period of 1924-2014. GEO also recorded approximately 9,000 man-made slope failures in the same period. Yet, an extreme storm can cause multiple hazardous processes besides landslides. During an intense rainfall event, part of the rainwater will infiltrate into the originally unsaturated soil slope and decrease the soil suction, causing slope failures (Zhang et al. 2011). The excess rainwater will become surface runoff, causing flooding, surface erosion and debris flows when mixing with various sources of soil materials. For example, the June 2008 storm, with a 24-h rainfall amount of $623 \mathrm{~mm}$, caused about 1500 landslides, 900 debris flows and over 600 flood spots in Hong Kong. Figure 1 shows the landslides and channelized debris flows near the Hong Kong International Airport on Lan Tau Island, Hong Kong, during the June 2008 storm.

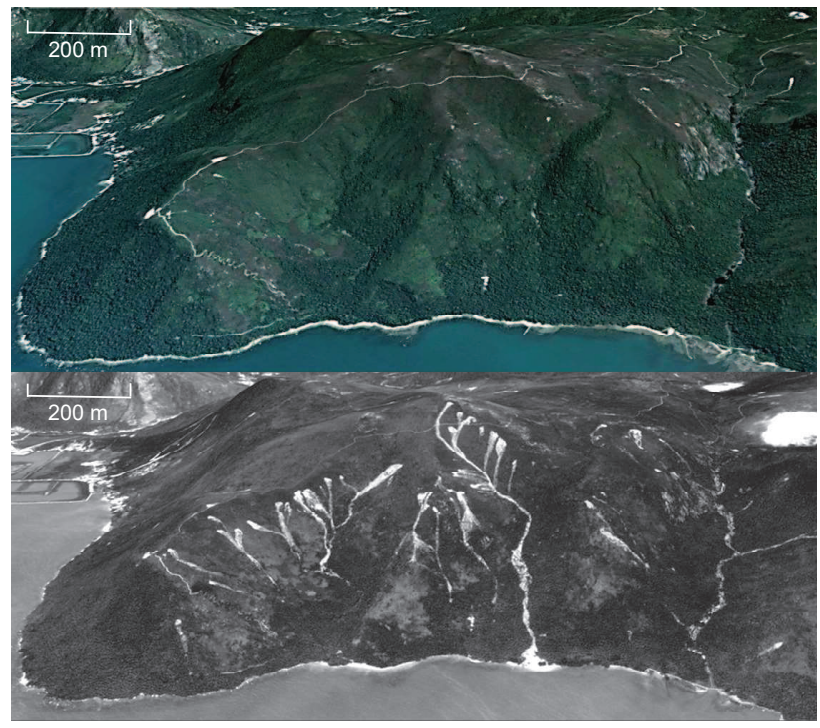

Figure 1. Landslides and channelized debris flows near the Hong Kong International Airport on Lan Tau Island, Hong Kong, during the June 2008 storm.

Storms and storm surges can cause catastrophic damage, as in New Orleans during Hurricane Katrina and in the New York and New Jersey during Hurricane Sandy in 2012. In September 2018 Hong Kong was hit by Typhoon Mangkhut. The wave height reached $4.71 \mathrm{~m}$ in Tai Po Kau and $3.88 \mathrm{~m}$ in Heng Fa Chuen on Hong Kong Island. Similar to Hurricane Sandy (Hashash et al. 2014), Typhoon Mangkhut caused the following consequences of geotechnical engineering interest: modification of the coastal geomorphology particularly coastal erosion, damage to coastal residential buildings and public infrastructural foundations, and disruption to buried structures and below ground infrastructure. Large areas of downtown South Tseung Kwan $\mathrm{O}$ and $\mathrm{Heng}$ Fa Chuen were flooded (Figs 2 a and b). The seawall along the Lohas Park shoreline was damaged, with heavy armor stones displaced and underneath fill washed away (Fig. 2c).

As a large city consists of many inter-related systems (transportation, utilities, communications etc.), the hazards caused by an extreme storm can evolve into a disaster chain with possible unknown future events. The hazards are highly correlated. The outcome of one event (e.g. flood) might be the cause of other events (shutdown of surface and underground transportation systems). Figure 3 summarizes the cascading hazards associated with Typhoon Mangkhut that hit the Pearl River Delta. The direct impacts included flooding, coastal erosion, slope failures, tree falling and building components. Subsequently these direct impacts led to technological hazards, such as fatalities from electrical shocks when electrical devices were inundated. Many infrastructural systems were paralyzed so that the social system could not operate after the end of the typhoon. For instance, Mangkhut caused over 60,800 cases of falling trees in Hong Kong. Much of the highway network 
was blocked by the falling trees and building debris, so that people could not return to work the next day, and many schools were still closed 4 days after the typhoon. Principles of system interactions may be referred to Gill and Malamud (2016), among others.
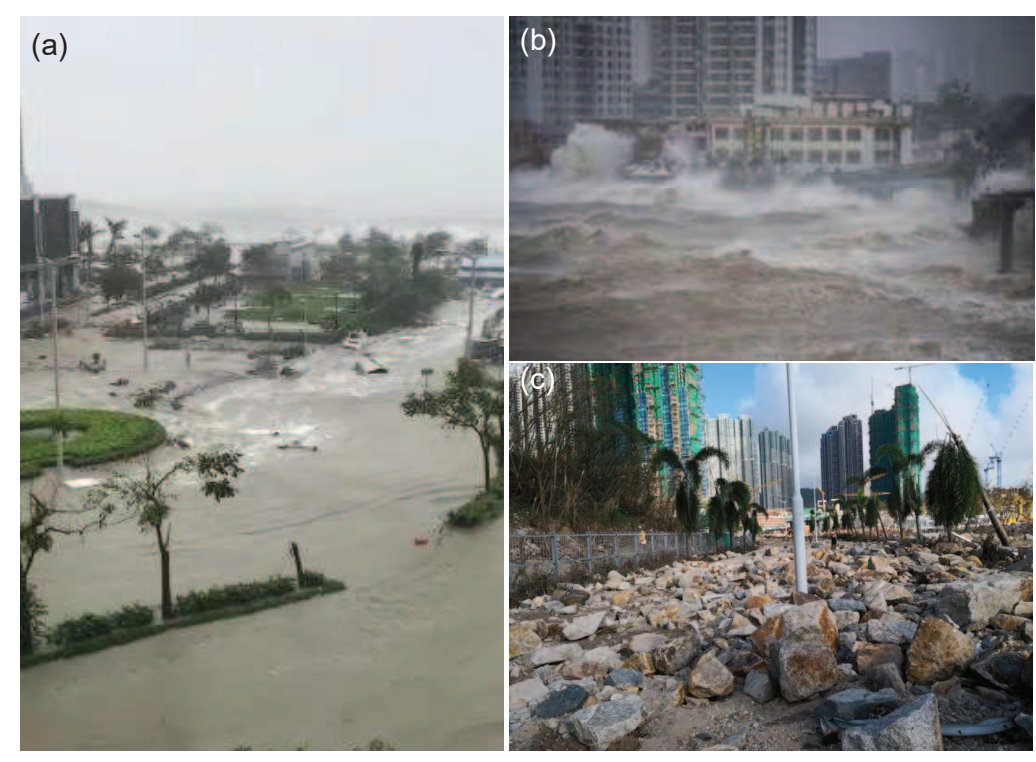

Figure 2. Damage to the urban areas of Hong Kong by Typhoon Mangkhut in Sept. 2018: (a) flooding of South Tseung Kwan O; (b) wave impact on the shoreline at Heng Fa Chuen; (c) street covered by fill materials washed away from seawall.

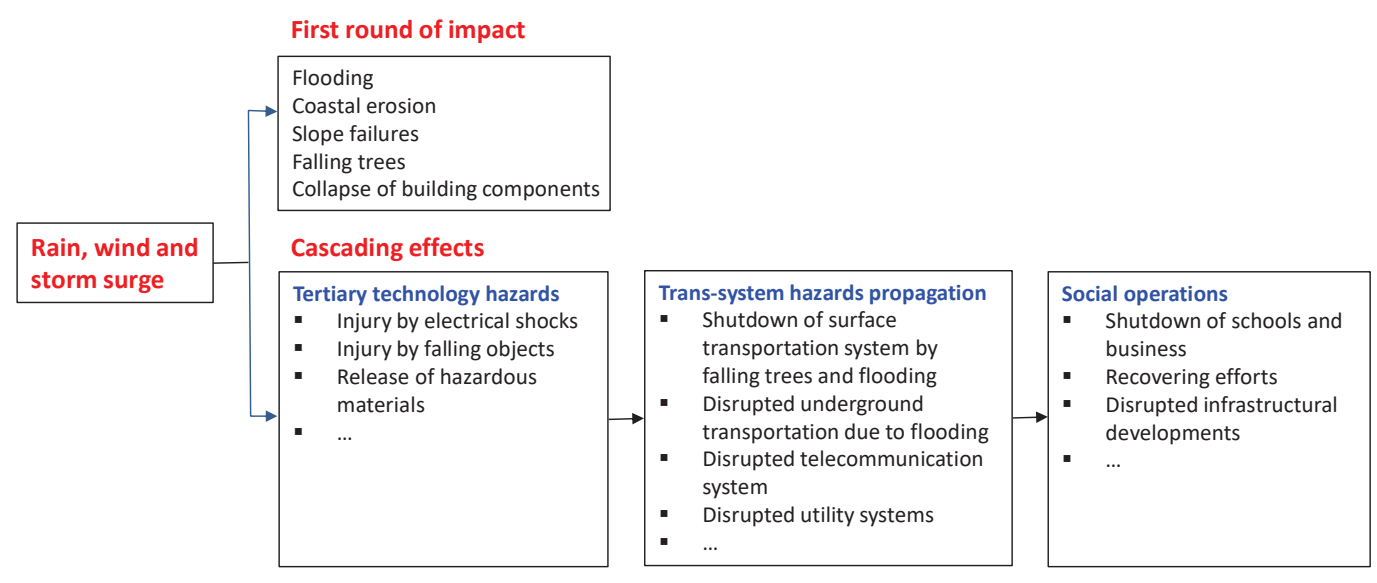

Figure 3. Cascading effects associated with extreme storms and storm surges observed during Typhoon Mangkhut in 2018.

\section{Plausible Future Storm Scenarios}

Hong Kong has been hit by more than 10 severe rainstorms in the past 30 years (1989-2019) with 24-hour rainfall of 500-956 $\mathrm{mm}$ and 4-day rainfall up to $1,450 \mathrm{~mm}$ (Gao et al. 2017a 2018). Although long-term climate may be simulated considering the effects of climate change (Intergovernmental Panel on Climate Change 2013), uncertainties associated with such simulations are rather high. The magnitudes of extreme storms are often characterized by the probable maximum precipitation (PMP) instead. The 24-hour PMP for Hong Kong has been assessed by AECOM and Lin (2015). The maximum rolling 24-hour rainfall during the 6-7 June 2008 storm at the storm centre corresponds to about $44 \%$ of the 24 -hour PMP.

Historical records have revealed that extreme rainfall events can be expected to be more frequent and intense in Hong Kong due to climate changes (e.g. Lee et al. 2008; Ho et al. 2016). The 30-year average annual total rainfall increased from 2,214 $\mathrm{mm}$ in the $1961-1990$ period to $2,398 \mathrm{~mm}$ in the $1981-2010$ period. The 
annual number of heavy rain days (days with hourly rainfall greater than $30 \mathrm{~mm}$ ) have also increased at an average rate of 0.3 days per decade from 1947 to 2014. These changes could have implications on urban hazards.

Given a designated PMP value, a design rain field may be synthesized as a moving rotated ellipsoid trend surface and a random field of residuals. The principal directions of the surface trend are between $25^{\circ}$ and $45^{\circ}$ for the particular topographic conditions in Hong Kong. The scales of fluctuation of the detrended residuals are found between $5 \mathrm{~km}$ and $25 \mathrm{~km}$ according to the semi-variograms and autocorrelation functions developed by Gao et al. (2017a). The uncertainties associated with the rain field are very high, particularly when the simulation of long-term climate is involved. A large number of random rain fields may be generated to cover likely storm scenarios for hazard simulations and associated risk analyses.
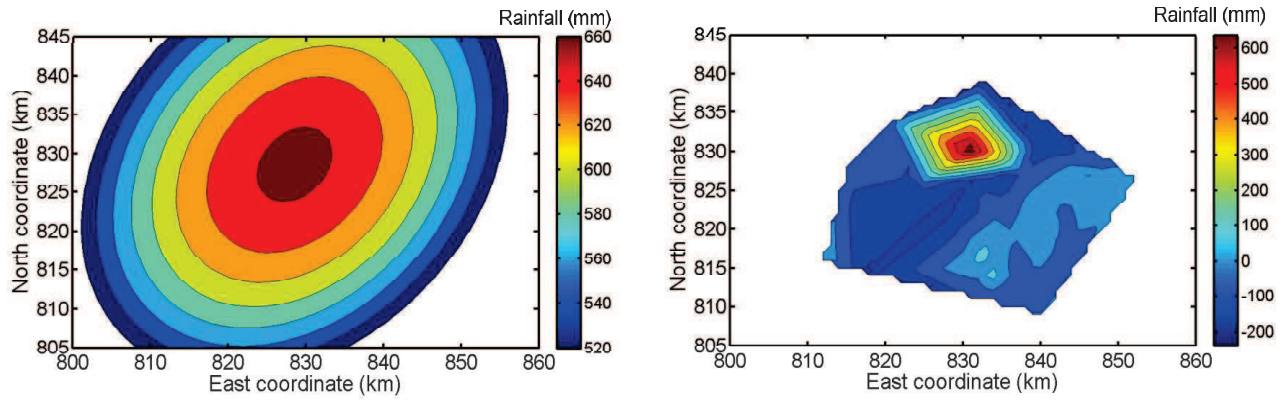

Figure 4. Trend surface (left) and residuals (right) of the total rainfall for the 22-24 July 1994 storm (after Gao et al. 2017).

Extreme wave conditions in Hong Kong are due to typhoons. The 200-year return period sea level at Tai Po Kau is $4.6 \mathrm{mPD}$ based on observations in the period of 1962-1999 (CED 2002). The wave height at Tai Po Kau was $4.71 \mathrm{~m}$ above the Chart Datum (4.56 mPD) during Typhoon Mangkhut in September 2018, and 4.09 above the Chart Datum during Typhoon Hato in August 2017. The wave height is significantly affected by tide. The maximum heights of storm surge and tide at Tao Po Kau during Typhoon Mangkhut were $3.41 \mathrm{~m}$ and $1.3 \mathrm{~m}$, respectively. The wave height would have by far exceeded the 200 -year return period level if high tide had occurred. For instance, if the tide were at a daily high level of $2.3 \mathrm{~m}$, the sea level would have been $5.71 \mathrm{~m}$ above the Chart Datum. The destruction to Hong Kong would have been much intensified. Offshore wave height can be significantly larger. For instance, the wave height from Storm Hindcasting at Location $\left(114^{\circ} 40^{\prime} \mathrm{E}, 21^{\circ} 55^{\prime} \mathrm{N}\right)$, approximately $50 \mathrm{~km}$ southeast Hong Kong, was $15.6 \mathrm{~m}$ (CED 2002). Due to limited wave height observation data in the Hong Kong area, the determination of future extreme wave heights considering climate change is still an open issue.

\section{Numerical Simulation of Response of Entire Hong Kong Territory to Extreme Storms}

\subsection{Characterizing the natural terrain and urban environment of the territory of Hong Kong}

Hong Kong has a land area of $1,073 \mathrm{~km}^{2}$. About 40 per cent of the land area is country parks and nature reserves. The terrain in Hong Kong is hilly (Fig. 5): approximately 63\% of the terrain is steeper than $15^{\circ}$ and $30 \%$ is steeper than $30^{\circ}$. The highest point is Tai Mo Shan, $957 \mathrm{~m}$ above the mean sea level. Urban developments are mostly on Hong Kong Island, Kowloon and several new towns in the New Territories. Due to the lack of flat land, the developments often extend to steep slopes where the terrain is too steep to develop. Hence densely populated areas are often at the foothill of or on steep terrains. Under extreme rainfall conditions, landslides and debris flows originating from the steep terrain can run into highly developed urban areas, creating a unique scientific problem of complex metropolitan multi-hazard risk assessment. Such assessment is rarely performed worldwide.

To evaluate the territory-wide urban hazard risks (excluding small islands), the terrain (Figs. 5 and 6a), the superficial geomaterials and their mechanical properties, buildings and infrastructures (Fig. 6a), the surface and underground drainage system (Fig. 6b), and the elements at risk (i.e. distribution of buildings and population in Fig. 6a) have to be characterized. Thanks to modern technology, the terrain and building profiles in Hong Kong can now be described precisely using LiDar based digital elevation model and building shape file, with resolution of 0.1-0.3 m. Buildings in urban areas may block the debris flow or runoff, or change its flow route. Hence it is necessary to consider the buildings in urban areas. The vector data of buildings, as polygon shapefile (.shp), can be transformed to a Raster format as input on the GIS platform (Gao et al. 2016). The geotechnical characterization of the superficial geomaterials at a city or territory scale, however, remains a huge challenge. 


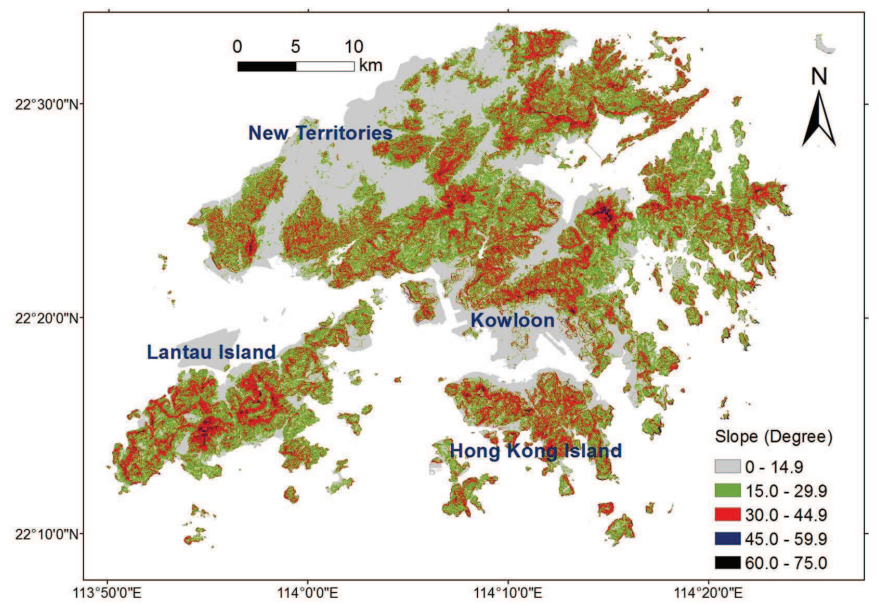

Figure 5. Study area and gradient of terrain: entire territory of Hong Kong excluding small islands.

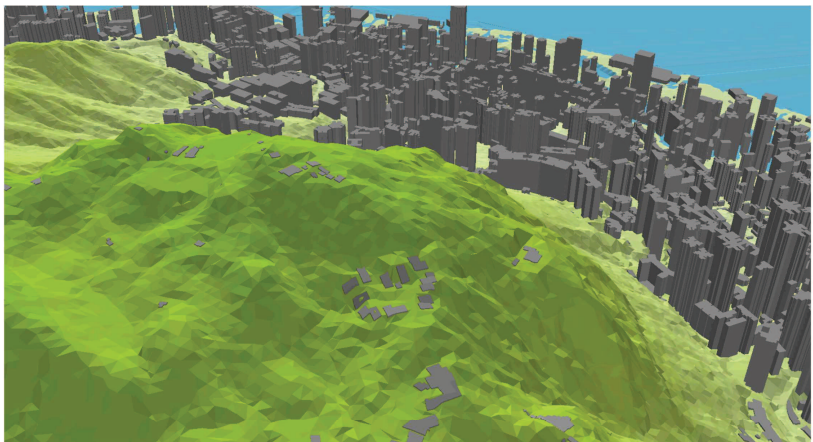

(a)

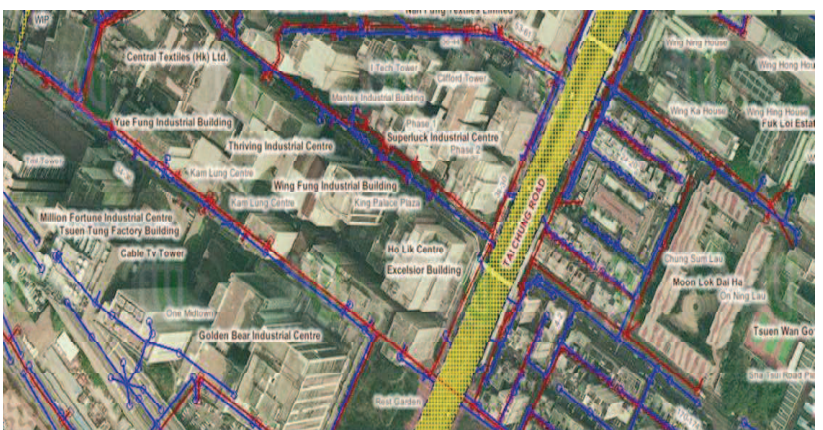

(b)

Figure 6. (a) Digital terrain and building distribution; (b) urban drainage pipeline and manhole layout.

\subsection{Multi-hazard simulation algorithms}

During a storm, multiple hazardous processes, namely wind, flooding, landslides, storm surge scour, hillslope erosion, and debris flows, can be initiated. Simulating such multi-hazard processes is challenging and constitutes a long-standing research topic. Intense rainfall in mountainous regions could trigger debris flows from loose soil deposits on hill slopes or in channels. The authors simulated the integrated process from temporarily and spatially distributed rainfall to surface runoff, infiltration and underground drainage, then to triggering of landslides due to rainfall infiltration, and finally to surface erosion and initiation of debris flows (Chen and Zhang 2014, 2015; Shen et al. 2017; Gao et al. 2017b, 2019).

A conceptual model for integrated simulation of slope failures, flooding, hillslope erosion and debris flow is shown in Fig. 7. Due to rainfall infiltration, the hill slope gradually becomes saturated, and the soil loses its 
strength, causing shallow seated slope failures (Zhang et al. 2011). Slope failures can occur at different times in space within a catchment. Some of the detached material may move into channels and form landslide dams, and some may transform into debris flows directly. As the surface runoff accumulates, landslide dams formed earlier in the channel may break, initiating a channelized debris flow. At the same time, the surface runoff may cause bed erosion and initiate hillslope debris flows. Some of the separate debris flows may merge in the main channel of the drainage basin, forming a larger catastrophic debris flow event. The final volume of a debris flow could be many times its initial volume due to entrainment of materials along the path from additional slope failures, bed erosion or channel wall collapses.

Based on the conceptual model in Fig. 7, the strategy of an integrated multi-hazard simulation model is shown in Fig. 8. The integrated model consists of a digital terrain module, a rainfall module, an infiltration module, an overland flow module, a slope stability module, a surface erosion module, a debris flow dynamics module and a deposition module. The digital terrain module discretizes the study area into a grid system with geological, hydrological and geotechnical information for each cell assigned. All the computations are based on the concept of cell. As the primary triggering factor, rainfall is simulated in the rainfall module. Then water infiltration into the ground is simulated to analyze the pore water pressure profile and compute the surface runoff. The slope stability and surface erosion are then evaluated in the slope stability module and surface erosion module, respectively. Once debris flows are initiated by the two physical mechanisms, the motion of the flowing mixture is analyzed through the debris flow dynamics module. Material entrainment may occur along the flow path, incorporating solid materials from addition slope failures and surface erosion. Finally, the deposition process is assessed through the deposition module. The runout distance, inundation area and deposition volume of the debris flows can all be assessed.

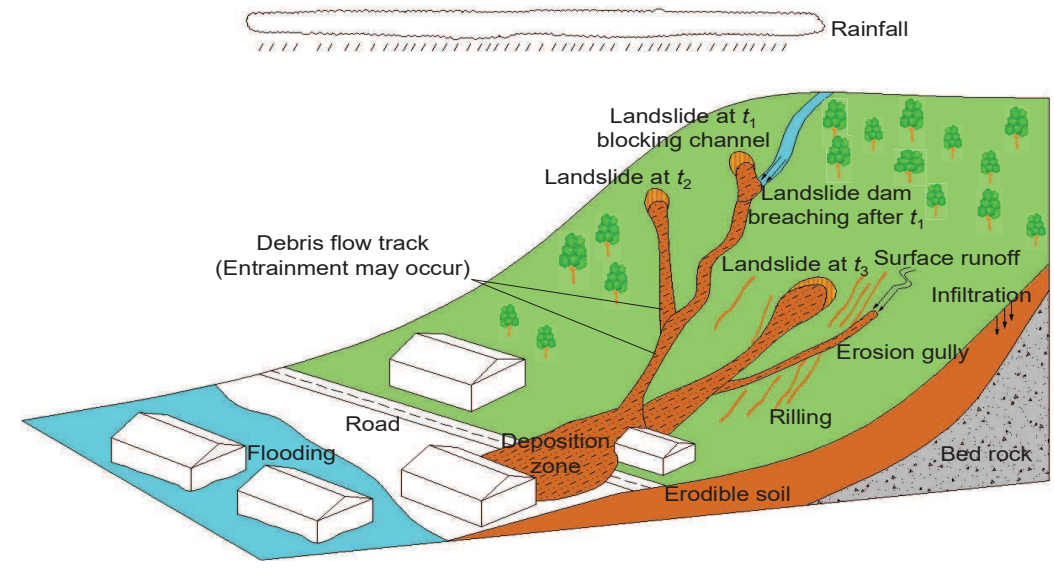

Figure 7. Conceptual model of a rain-induced debris flow and three typical initiation mechanisms of debris flows: bed erosion, transformation from landslide, and dam breach.

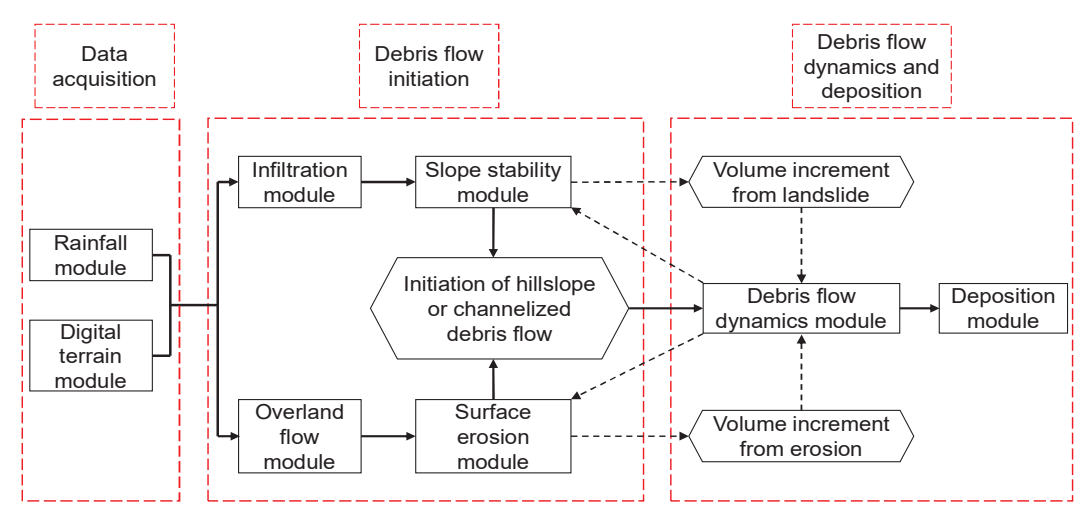

Figure 8. Framework of integrated simulation of debris flows.

The core of the proposed integrated analysis is the mixture-flow dynamics simulation and constitutive modelling of the flowing mixture. The governing equations for debris flow dynamics describe the mixture 
movement and changes in debris flow properties, which are depth-integrated mass conservation equations (Equations 1 and 2) and momentum conservation equations (Equations 3) (Chen and Zhang 2015):

$$
\begin{aligned}
& \frac{\partial h}{\partial t}+\frac{\partial(h v)}{\partial x}=i\left[C_{v^{*}}+\left(1-C_{v^{*}}\right) s_{b}\right]+A\left[C_{v A}+\left(1-C_{v A}\right) s_{A}\right] \\
& \frac{\partial\left(C_{v} h\right)}{\partial t}+\frac{\partial\left(C_{v} h v\right)}{\partial x}+=i C_{v^{*}}+A C_{v A} \\
& \frac{\partial v}{\partial t}+v \frac{\partial v}{\partial x}=g\left[-\operatorname{sgn}(v) S_{f}-\frac{\partial\left(z_{b}+h\right)}{\partial x}\right] \\
& -\frac{v\left\{i\left[C_{v^{*}}+\left(1-C_{v^{*}}\right) s_{b}\right]+A\left[C_{v A}+\left(1-C_{v A}\right) s_{A}\right]\right\}}{h}
\end{aligned}
$$

where $h$ is the flow depth; $v$ is the depth-integrated flow velocity $(\mathrm{m} / \mathrm{s}) ; i$ is the erosion rate $(>0)$ or deposition rate $(<0)(\mathrm{m} / \mathrm{s}) ; A$ is the rate of material entrainment from detached landslide materials $(\mathrm{m} / \mathrm{s}) ; C_{v}$ is the volume fraction of solids in the flowing mixture; $C_{v^{*}}$ and $C_{v A}$ are the volume fraction in the erodible bed and in the entrained materials, respectively; $s_{b}$ and $s_{A}$ are the degree of saturation of solids in the erodible bed and in the entrained materials, respectively; $S_{f}$ is the energy slope; $z_{b}$ is the bed elevation $(\mathrm{m})$; and the sgn function is used to ensure that the direction of the flow resistance is opposite to that of the flow direction.

One of the requirements of the integrated analysis is modeling different flowing mixtures simultaneously. The flowing mixture can be classified into three types: clear water flow, hyper-concentrated flow, and fully developed debris flow based on sediment concentration, combining grain-size distribution and particle densities.

The surface hydrology and hydraulics and the storm draining process through the drainage networks need to be simulated simultaneously. The drainage hydraulic process is simulated using the embedded Storm Water Management Model (SWMM) based on the 1-D Saint-Venant equations for the conservation of mass and momentum that govern the unsteady flow of water through a network of pipes (Huber et al. 2005). To integrate the drainage hydraulic process with the overland flow process, the junctions in the storm drainage system (Fig. 6b) are set up as inlets or outlets, and recognized in the cells of the overland flow module. Cells assigned as inlets/outlets connect the surface layer with the closed conduit storm drainage system. The storm drainage module solves the drainage hydraulics by integrating the inlet/outlet discharges for each computational time step.

\subsection{Modelling territory-wide multi-hazard processes}

Territory-wide multi-hazard processes in Hong Kong are being simulated using the integrated numerical simulation platform. The flood response to selected extreme storms over the territory of Hong Kong, excluding small islands, and the multi-hazards processes on Hong Kong Islands are presented. The assumed storm of $65 \%$ of the 24-h PMP, shown in Fig. 9, corresponds to the maximum rainfall in the history of Hong Kong, with a total rainfall of $982 \mathrm{~mm}$.

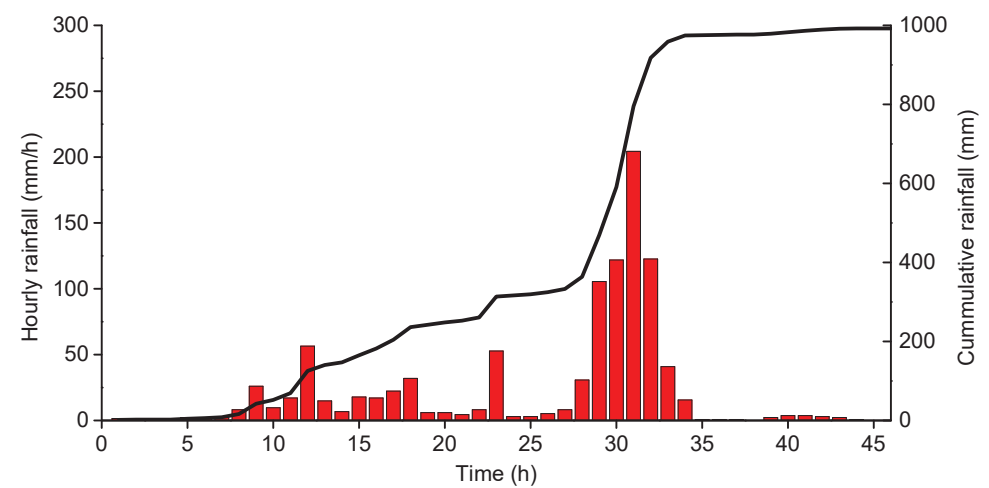

Figure 9. Hyetograph of the assumed storm corresponding to $65 \%$ of $24-\mathrm{h}$ PMP with a total rainfall of $982 \mathrm{~mm}$.

The flooding scenarios across the entire Hong Kong, except small islands, have been simulated under various likely rainstorm conditions. Figure 10 show the simulated flood hazard levels upon storms of $29 \%$ and $65 \%$ of the 24-h PMP, with total rainfall amounts of $438 \mathrm{~mm}$ and $982 \mathrm{~mm}$, respectively. Following similar criteria of Meon et al. (2006), the hazard level is considered high when the water depth $h$ is greater than $1.5 \mathrm{~m}$ or the product of water depth $h$ and flow velocity $v$ is $h v \geq 1.5 \mathrm{~m}^{2} / \mathrm{s}$, medium when $0.5 \mathrm{~m} \leq h<1.5 \mathrm{~m}$ or $0.5 \leq h v<$ $1.5 \mathrm{~m}^{2} / \mathrm{s}$, and low when $h<0.5 \mathrm{~m}$ or $h v<0.5 \mathrm{~m}^{2} / \mathrm{s}$. Based on the analyses, numerous vulnerable areas are identified, particularly Mai Po, Kam Tin and Lam Tsuen Valley on northwest New territories, Ting Kok and Tai 
Wai on east New Territories, To Kwa Wan and Kwun Tong in Kowloon, Happy Valley and Sheung Wan on Hong Kong Island, and Tai O on Lan Tau Island. The simulation results agree well with the observed flood black spots in the past. Particularly, upon a storm of $65 \%$ PMP, the flood hazard level will increase significantly compared with that upon a storm of $29 \%$ PMP. Some strategical areas for near-future development, such as Kwu Tung, are at high flood risk. Note that the current flood control measures (i.e., the urban storm water system, the drainage tunnels and the underground storage tanks) have been considered in the analyses. The presence of extensive high hazard zones implies that additional engineering measures are needed and that warning and evacuation will serve as essential means to reduce the flood risk that cannot be contained economically through engineering measures.

Figure 11 presents the simulated landslide scars, landslide deposits, and debris flow distributions on Hong Kong Island under a rainstorm corresponding to a 65\% of 24-h PMP (After Zhou et al. 2019). The Island has an area of $78.59 \mathrm{~km}^{2}$; the highest point is Victoria Peak with an elevation of $551.7 \mathrm{~m}$. The analysis models are validated with historical debris flows triggered by the rainstorm in 2008. In the simulation, a slope stability

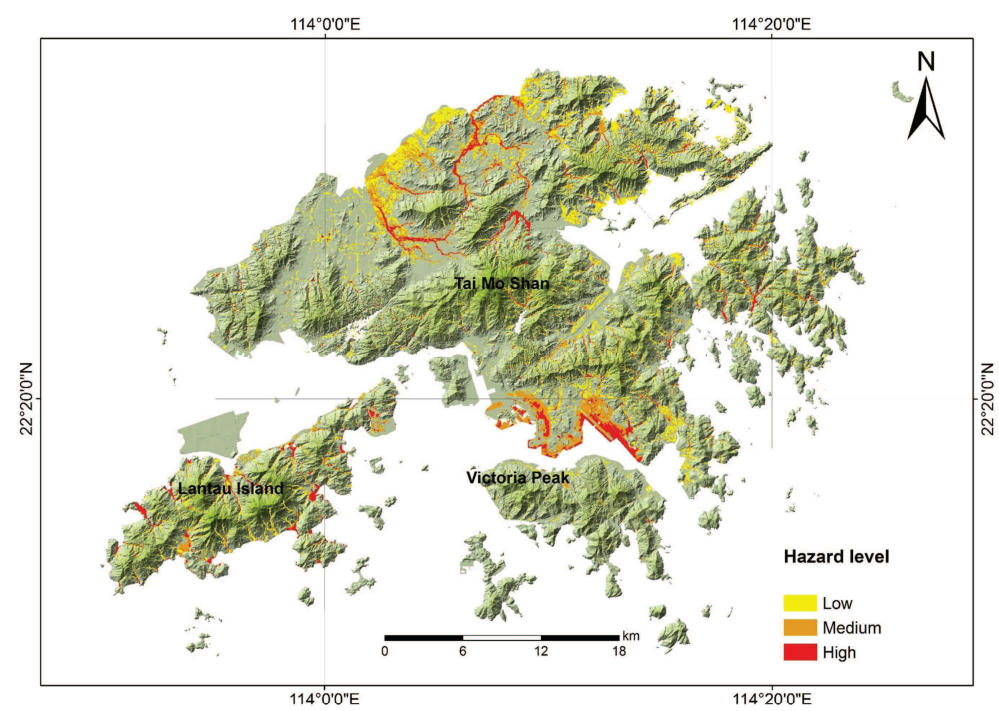

(a)

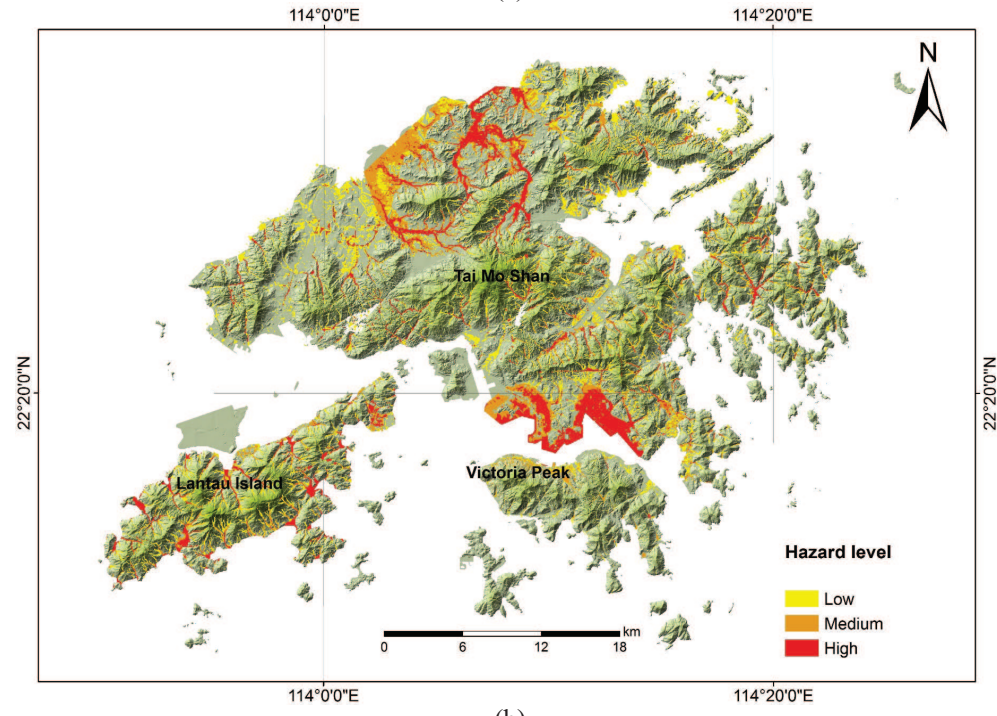

(b)

Figure 10. Flood hazard levels across the entire Hong Kong under (a) a storm of $29 \%$ and (b) a storm of $65 \%$ of $24-h$ PMP. analysis is conducted and unstable cells and landslide deposition areas are identified. The clusters of debris flows initiate from the landslide scars, and debris flow dynamics is simulated considering hillslope erosion or material entrainment. From the prediction of the slope failures, the total soil deposit volume may reach $1.1 \times 10^{6} \mathrm{~m}^{3}$. If one third of the landslide material evolves into debris flows, the total volume of debris flow may amplify to $0.73 \times 10^{6}$ 
$\mathrm{m}^{3}$, affecting $2.6 \mathrm{~km}^{2}$ or $3.3 \%$ of the natural terrain of the Hong Kong Island. The likely locations of landslides and debris flows in Fig. 11 provide more quantitative information for risk mitigation than conventional statistical correlations do.

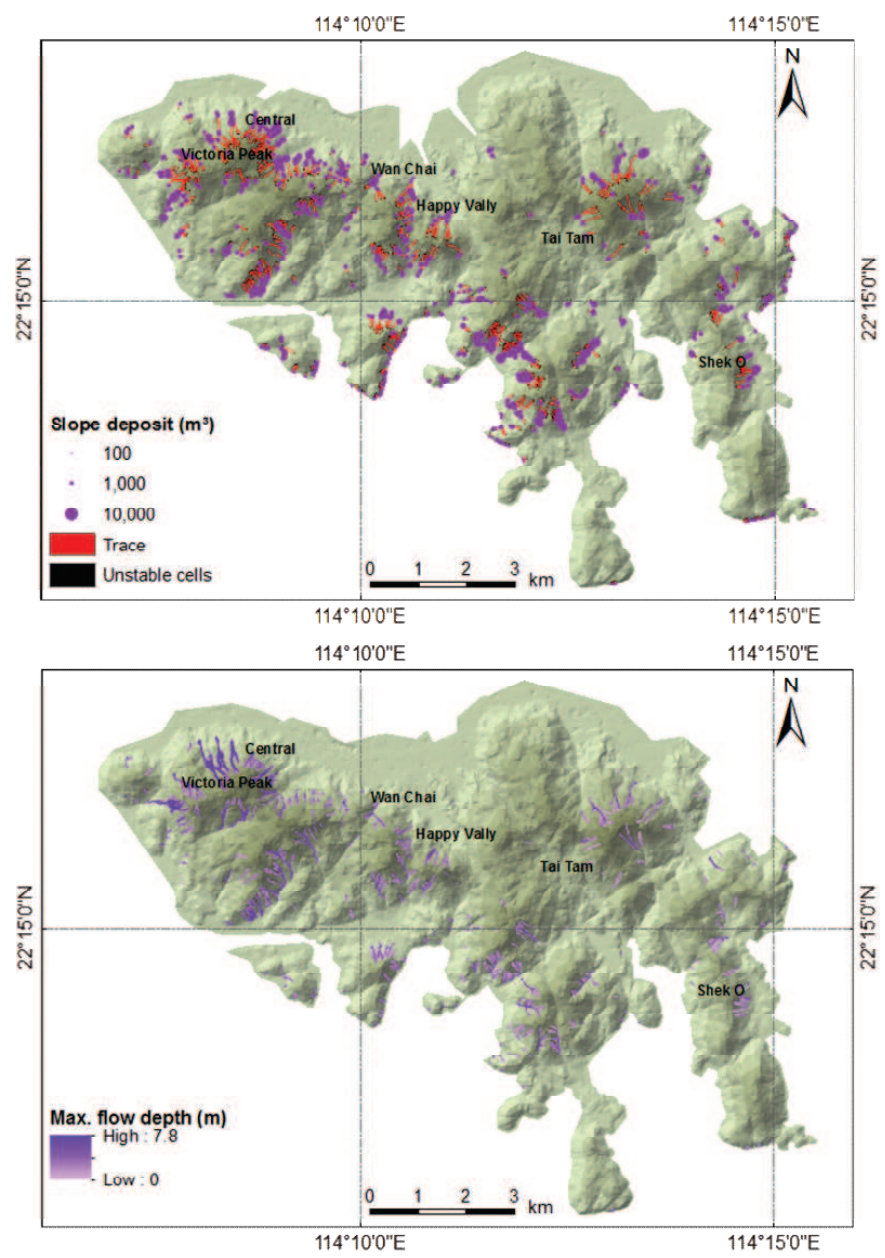

Figure 11. Simulation results of (a) landslide deposits and landslide scars and (b) maximum debris flow depth corresponding to a $65 \%$ of 24-h PMP (After Zhou et al. 2019).

\section{Urban Risk Mitigation Strategies}

A five-phase procedure proposed by Zhang and Zhang $(2014,2017)$ has been implemented in a numerical code (Chen et al. 2016) to assess large-scale landslide and debris flow risks. The five phases include definition, multihazard assessment, exposure assessment, multi-vulnerability assessment and multi-risk assessment. The code adopts a cell-based platform to achieve efficient multi-hazard risk assessment. The study area is discretized into a GIS-based grid system as in the numerical simulations (Chen and Zhang 2015; Shen et al. 2018). Hazard analysis and risk assessment are conducted cell by cell automatically. The platform is able to promptly identify overlapping areas by multiple hazards. Hazard interactions are partially considered by including increased vulnerabilities to individual hazards when hazards overlap and deducting overlapping risks. Effort is being made to include flooding in the risk analysis.

Hong Kong is exploring green technologies to mitigate urban multi-hazard risks. The major strategies include (Fig. 12):

1. Stabilise the hillslopes using green stabilization techniques such as soil nails and re-compaction layers with a vegetation cover. The soil nails or re-compaction stabilise the slopes against sliding while the vegetation cover prevents surface erosion and adds ecologic value. 
2. Protect elements at risks using green barriers at the foothill. Eco-friendly flexible barriers are particularly promoted as they comply well with natural irregular terrain and native vegetation, and do not alter the natural beauty.

3. Enhanced drainage at both mid-levels and low-lying urban areas. Hong Kong has been a pioneer in the use of mid-level drainage tunnels to minimise the stormwater from running into the urban area, and the use of underground storage tanks to temporarily store floodwater during an intense storm and release the floodwater afterwards. For instance, the $11 \mathrm{~km}$ Western Hong Kong Island Drainage Tunnel was commissioned in 2012; the $3.7 \mathrm{~km}$ long Lai Chi Kok Drainage Tunnel in 2012; the Sheung Wan Flood Relief Project in 2009 and the Happy Valley Underground Stormwater Storage Tank in 2017. Gao et al. (2019) evaluated the flood coping capabilities of some of these new facilities under heavy storms.

4. Although engineering risk mitigation measures are intended to meet a major social need, the densely urbanized area may still suffer flooding and landslide risks when severe storm events occur. Hence the present engineering design standard may need to be raised and non-structural measures such as warning and evacuation adopted to cater for the future extreme rainfall conditions.

Recent strong typhoon events called for enhanced coastal resilience. However, appropriate strategies for enhancing flood defence in the changing climate while preserving the beauty of the Victory Harbour and the promenade across Hong Kong are yet to be developed.

The performance of any proposed green technologies may be checked against one or several of the five GREAT attributes of smart cities (i.e. green, resilient, empowering, adaptable and transformative). Among others, a stress-testing approach has been proposed to test the 'resilient' aspect, namely to evaluate the engineering system response under plausible future storms and the corresponding vulnerable elements and risks (Zhang et al. 2017).

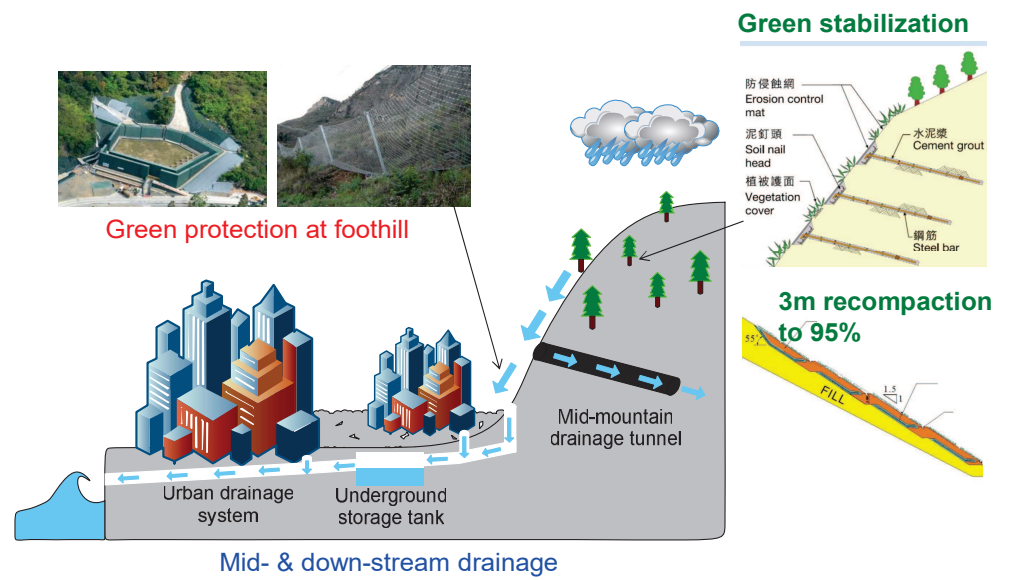

Figure 12. Green technologies for mitigating urban flooding, landslide and debris flow risks.

\section{Summary}

This paper presented a metropolitan resilience study when facing extreme storms, taking Hong Kong as a study city. The following conclusions may be drawn:

1. In the changing climate, the rapidly developing metropolitans are exposed to increased multi-hazard risks. Hence urban resilience is a key indicator of a modern city.

2. A large city is a system of many highly interactive physical and social systems; the hazards from extreme weather can propagate from one system to another, forming a hazard chain.

3. Taking Hong Kong as a test bed, efforts are being made to characterize the urban environment and simulate the multi-hazard processes caused by extreme rainfall over the entire territory on a digital platform. Through such analyses, the impacts of extreme storms can be presented and vulnerable elements can be identified.

4. Green technologies have been recommended for coping with the multi-hazard risks in the changing climate, which include stabilization at sources of hazards, protection of elements at risk at foothill and drainage at low-lying areas. The performance of any green technology may be checked against one or several of the five GREAT attributes of smart cities (i.e. green, resilient, empowering, adaptable and transformative).

5. Even after engineering measures are taken, the risk levels in the urban areas upon an extreme storm can still be very high. Hence non-structural measures, such as warning and evacuation, play an increasingly important role in coping with risks of extreme storms. 
6. Uncertainties in future storm scenarios and city-scale geotechnical characterization remain major challenges.

\section{Acknowledgments}

The authors acknowledge the support from the Science and Technology Plan of Shenzhen (No. JCYC20180507183854827) and the Research Grants Council of the Hong Kong SAR (Grant No. C6126-15G), as well as the technical comments from Prof. Hsein Juang and Prof. Jie Zhang.

\section{References}

AECOM and Lin, B. (2015). 24-hour probable maximum precipitation updating study. GEO Report No. 314, Geotechnical Engineering Office, the Government of the Hong Kong Special Administrative Region.

CED (Civil Engineering Department). (2002). Port Works Design Manual-PART 1 General Design Considerations for Marine Works, the Government of the Hong Kong Special Administrative Region.

Chen, H.X. and Zhang, L.M. (2014). A physically-based distributed cell model for predicting regional rainfall-induced shallow slope failures. Engineering Geology, 176, 79-92.

Chen, H.X. and Zhang, L.M. (2015). EDDA 1.0: integrated simulation of debris flow erosion, deposition and property changes. Geoscientific Model Development, 8, 829-844.

Chen, H.X., Zhang, S., Peng, M., and Zhang, L.M. (2016). A physically-based multi-hazard risk assessment platform for regional rainfall-induced slope failures and debris flows. Engineering Geology, 203, 15-29.

Gao, L., Zhang, L.M., and Cheung, R.W.M. (2018). Relationships between natural terrain landslide magnitudes and triggering rainfall based on a large landslide inventory in Hong Kong. Landslides, 15, 727-740.

Gao, L., Zhang, L.M., Chen, H.X., and Shen, P. (2016). Simulating debris flow mobility in urban settings. Engineering Geology, 214, 67-78.

Gao, L., Zhang, L.M., Li, X.Y., and Zhou, S.Y. (2019). Evaluating metropolitan flood coping capabilities under heavy storms. Journal of Hydrologic Engineering, ASCE, 24(6), 05019011.

Gao, L., Zhang, L.M., and Lu, M.Q. (2017a). Characterizing the spatial variations and correlations of large rainstorms for landslide study. Hydrology and Earth System Sciences, 21, 4573-4589.

Gao, L., Zhang, L.M., and Chen, H.X. (2017b). Likely scenarios of natural terrain shallow slope failures on Hong Kong Island under extreme storms. Natural Hazards Review, ASCE, 18(1), B4015001.

Gill, J.C. and Malamud, B.D. (2016). Hazard interactions and interaction networks. Earth System Dynamics, 7, 659-679.

Hashash, Y.M.A., Nikolaou, S., Sukumaran, B., Sacks, A., Burlingame, M., Baxter, C., Bradshaw, A., Wooten, L., Lacy, H., Moss, C., Daraio, J., and O'Rourke, T.D. (2014). Selected effects of the 2012 Hurricane Sandy along the US east coast: A geotechnical perspective. Geo-Congress 2014, Geotechnical Special Publication No. 235, Reston, ASCE, 28-58.

Ho, K.K.S., Sun, H.W., Wong, A.C.W., Yam, C.F., and Lee, S.M. (2016) Enhancing slope safety preparedness for extreme rainfall and potential climate change impacts in Hong Kong. Region Report for Hong Kong. Preparedness for Climate Change Impact on Slope Safety (eds: Ho, K.K.S., Lacasse, S. and Picarelli, L.). Taylor \& Francis, London, 104-146.

Huber, W.C., Rossman, L.A., and Dickinson, R.A. (2005). EPA Storm Water Management Model SWMM 5.0, Watershed Modelling, CRC Press, Boca Raton, FL.

Intergovernmental Panel on Climate Change (2013). Climate Change 2013: The Physical Science Basis, The Fifth Assessment Report. https:/www.ipcc.ch/site/assets/uploads/2018/03/WG1AR5_SummaryVolume_FINAL.pdf.

Lee, T.C., Leung, W.H., and Ginn, E.W.L. (2008). Rainfall projections for Hong Kong based on the IPCC fourth assessment report. Reprint 798, Hong Kong Observatory, Hong Kong.

Lo, H.K. (2018). Director's message - GREAT Smart Cities Centre, https://gsc.ust.hk/director-message.

Meon, G., Kleeberg, H.B., Röttcher, K., and Spanknebel, H.G. (2006). Flood Hazard Map Guidelines of the German Working Group of the Federal States on Water Issues (LAWA), Bund/Länder-Arbeitsgemeinschaft, Wasser.

Shen, P., Zhang, L.M., Chen, H.X., and Fan, R.L. (2018). EDDA 2.0: integrated simulation of debris flow initiation and dynamics considering two initiation mechanisms. Geoscientific Model Development, 11(7), 2841-2856.

Zhang, L.L., Zhang, J., Zhang, L.M., and Tang, W.H. (2011). Stability analysis of rainfall-induced slope failures: A review. Geotechnical Engineering, Proceedings of the Institution of Civil Engineers, 164(5), 299-316.

Zhang, L.M., Gao, L., Zhou, S.Y., Cheung, R.W.M., and Lacasse, S. (2017). Stress testing framework for managing landslide risks under extreme storms. 4th World Landslide Forum (WLF4), Ljubljana, Slovenia, 29 May - 2 Jun 2017, Springer International Publishing AG 2017, M. Mikoš et al. (eds.), 17-32.

Zhang, L.M. and Zhang, S. (2014). Multi-risk landslide scenarios in geotechnical sustainability: A case study. Geo-Congress 2014, Atlanta, 23-26 Feb. 2014, GSP 234, ASCE, Reston, 3303-3312.

Zhang, L.M. and Zhang, S. (2017). Approaches to multi-hazard landslide risk assessment. Proc. ASCE GeoRisk 2017, 3-6 June 2017, Denver, USA. GSP No. 286, 312-323.

Zhou, S.Y., Gao, L., and Zhang, L.M. (2019). Predicting debris-flow clusters under extreme rainstorms: a case study on Hong Kong Island. Bulletin of Engineering Geology and the Environment, https://doi.org/10.1007/s10064-019-01504-3. 